appearance of a specimen is to be most strongly deprecated, unless, indeed, this has been deliberately undertaken for the express purpose of demonstrating some particular structural feature; yet many collectors are in the habit of making their specimens "look pretty." The conchologist removes the periostracum from his shells, treats them with acid or sil, and conceals any imperfection by aid of a file; the entomologist is said to be not above patching a damaged insect with parts taken from another specimen (not necessarily of the same species); and corals are occasionally provided with artificial bases of plaster of Paris.

The practice in vogue in many museums of mounting small specimens upon tablets is an exceedingly had one, since it greatly restricts any critical examination; moreover, the specimens are liable to be injured by the cement used.

Collectins' a Riepresentatize Serres of Speitinens. - As has been pointed out, scientific research necessitates the examination of large series of specimens exactly representing the form as it occurs at the particular station where the specimens were collected. The field naturalist will most readily ensure that a series shall conform to this condition by collecting every speci. men of the form in question which is observed during a certain period of work-five ninutes, an hour, a month, according to its abundance and variability. And, in order that small local variations may be rendered evident. the area over which the series is collected must be a small one. If now the whole gathering thus obtained is kept intact and unmixed with specimens collected on other occasions or at different stations, it may safely be regarded as fairly representing the species as it occurred at that particular time and place; and it will form a satisfac tory basis for comparison with similar series gathered elsewhere and at other seasons. It will probably he urged that this system of collecting is impracticable, as it will entail greater cabinet space. Granted that it may necessitate the provision of more storage room, but is not the usefulness of a collection the only excuse for its formation? And if more space is required it must be provided. IIowever, this objection is not nearly so serious as might be imagined; it is by no means necessary or even desiratble that enormous series of specimens should be displayed for exhibition in museum cases or cabinets; all that is required is that they should be stored in such a way as to be easily accessible when wanted for study. Thus in most cabinets much space is occupied by cotton-wool which could readily be filled with specimens without in the least adding to the bulk of the collection. In any case, whatever difficulties may be encountered they will have to be overcome, as only when large series of carefully localised specimens from numerous stations are gathered together in our museums and private collections will it be possible for any really scientific taxonomic work to be accomplished. Until this material is available it is useless to argue over rules of nomenclature and such like, as no satisfactory answer can yet be given to the fundamental question, "What is a species?"

\section{Variations of Atmospheric Electricity.}

I EXCLOSE a photograph of the tracings, recording the atmospheric electricity disturbances from January 4 to February 15 inclusive. The records are obtained in the following manner: Two antennee are used, one vertical 20 metres in length, its lower extremity connected to coherer. The other, 47 metres long, consisting of an ascending vertical portion of 20 metres, also connected below with same pole of coherer, a horizontal portion of 7 metres, and a descending vertical portion of 20 metres, the whole being the shape of an inverted $U$, going up one side of house, across the top and down the other side. These two antennie are carefully insulated. The other pole of coherer is connected to earth, in this case to the bottom of a deep well. The coherer closes the circuit of a relay, which in its turn closes the circuit of two electro-magnets, one of which draws up the style and so records a stroke on the revolving drum; the other sets a clockwork apparatus in movement which strikes coherer and so decoheres. The receiver is situated on a hill, overlooking the neighbouring country.

The disturbances seem at times to recur about the same time on successive days, or sometimes after an interval of a day or two. For instance, the first two on the $4^{\text {th }}$ and the first two on the gth seem to have some connection. Again, the second pair on the $g^{\text {th }}$ seem identical with the first pair on the 10 h.

Taking the central group on the 9 th, 10th, I2th, 14th, it might be subdivided into two groups, comnencing on the gth with two in each group, reaching its maximum on the loth, five and seven, and on the 12 th reduced to one in each group, finally, on the I 4 th, only one remaining in the stronger group, that is the one with a maximum of seven.

On February is there was one disturbance, on February is two, the first of which was at identically the same time as the one of the previous day. It would be interesting to compare the records of several receivers and see how far-reaching these disturbances are, or whether they are purely local phenomena. For this purpose two more receiving stations are shortly to be fitted up in this department. During the period covered by these records there have been no visible or audible signs of thunderstorms, and on many occasions the sky was cloudless, barometer high, thermometer low $-28^{\circ} \mathrm{F}$. to $36^{\circ} \mathrm{F}$. - during the last eight days of February, when there could have been no storms within several hundred miles.

Bellevue, Laroin, Pau, Basses Pyrénées, France.

\section{The Selborne Yew-tree.}

Gil.rerT WhIte, in his "Antiquities of Selborne," Chap. v. (Chandos Classics Edition) mentions a male yew growing in the churchyard. IIe believed it $(1)$ be some centuries old and states its girth as $23 \mathrm{ft}$. This afternoon I have, with Mr. L.ewis Eynon, remeasured the trunk and find it to be $25 \mathrm{ft}$. $6 \mathrm{in}$. The stem of this mapnificent tree is sfuat and rather bulging, and as White mentions its girth as something extraordinary, it is to be presumed that his measurement was made at the point of maximum diameter - about four fect from the ground. This is the height at which our figure was obtained, and we used a steel tape taken right round without regarding irregularities of surface. The increase in girth will be seen to correspond to a radial growth of 4.7 in. in the 120 years or so since IVhite's time. I know not whether recent measurements of this tree have been published, but the fact seems worthy of record.

75 Barry Road, Dulwich, S.E. March 16.

\title{
INJURIOUS CONSTITUENTS IN POTABLE SPIRITS
}

$A \mathrm{~N}$ interesting communication is just to hand, by $\mathrm{Sir}$ Lauder Brunton and Dr. Tunnicliffe, upon "Certain apparently injurious constituents of potable spirits." Its appearance now is certainly opportune, since, whatever else we may be interested in, alcoholic beverages are certainly attracting a deal of public attention at the present time. It is further, if not a relief, certainly a change, to learn that something else in alcoholic drinks besides arsenic and selenium may be the cause of mischief, and their removal advantagreous. Our mentation just now is rather apt to be over-arsenicated ; moreover, from the point of the consumer, the impurities discussed by these workers certainly seem to have one important advantage over arsenic, in that they can be completely removed-that is, removed to the satisfaction of the chemist as well as to that of the pharmacologist.

The subject of whiskey, with which the above monograph is concerned almost entirely, has not received very inuch attention at the hands of chemists, pharmacologists or dietetic experts, since the publication, in 1891 , of the report of the select Committee on British and Foreign Spirits. This Committee directed itself mainly to the question whether compulsory bonding, as practised in Canada, should be adopted in this country, and also whether any restrictions should be placed upon blending, as by, for instance, limiting the name whiskey to the product made from malt, or malt and grain, in a socalled pot-still. The result of the Committee, so far as legislation was concerned, was nil. In the course of the inquiry, however, many interesting pharmacological facts came out, and the present work must be looked upon as a continuation of what may be termed the pharmacology of whiskey. Readers who are interested in the subject are strongly recommended to consult the Blue Book, which contains a mass of most interesting and important information.

No. 1638 , voL. 63$]$ 
Certainly until the appearance of this report, and by many even to-day, fusel oil is regarded as par excellence the injurious constituent of whiskey. This substance, which is a mixture of varying proportions, according to the spirit, of butylic, propylic and amylic alcohols, has apparently been maligned, and is not, at any rate in the proportion in which it occurs in ordinary potable spirits, a source of much danger to the public health. The chief other impurities touched upon at this inquiry were furfural and aldehydes other than furfural. At that time very little was known concerning the action of furfural or the aldehydes, and it is especially in this connection that the monograph before us is of interest.

Although there can be no doubt that it is the ethyl alcohol that causes alcoholic intoxication, it appears that the actual way in which one grets drunk, or gets sober after being drunk, depends largely upon the quality of the liquor partaken of. (Ine of the most important factors in determining the quality is the content of the beverage in question in aldehydes, including furfural, another its content in certain volatile bases.

The source of furfural in the manufacture of whiskey is a class of substances known as pentosans; these are derived from the cellulose of the grain husks, and under the influence of heat, in the presence of acids, are in the wash still converted into furfural. Furfural is present in all pot-still whiskeys, and also obviously to a less extent in those patent still whiskeys which are blended with the real pot-still products to give them the taste of whiskey. Any one can apparently demonstrate for himself quite simply the presence of furfural in whiskey. It is simply necessary to dilute the whiskey and to add to it a few drops of an aniline acetate solution; almost immediately the whiskey becomes rose-coloured and later deep rose changing to light purple according to the quantity of furfural present.

In addition to furfural there are also present in whiskey other aldehydes. Speaking generally, these bodies are poisonous, or at least irritating; they are for the most part converted in the body into the corresponding acid, and thus tend to diminish the alkalinity of the blood. This individual point is not without interest in that, according to most physicians, any cause tending to render the blood less alkaline favours the occurrence of gouty deposits in the joints.

The experimental inquiry concerns itself more especially with the action of furfural upon animals and man This substance, according to Sir Lauder Brunton and Dr. Tunnicliffe, gives rise to paralysis of the voluntary muscles, and later to clonic and tonic convulsions. An odd point about these symptoms is their transient nature; immediately after the injection of the drug the animal would fall down completely paralysed, its tongue and lips would become bluish and its breath ing slow and convulsive, at other times irregular and rapid; convulsions would then appear, vomiting would occur, and then the animal would begin to recover, being at first dazed but becoming rapidly normal. Two human subjects who were bold enough to take this apparently active poison in the same dose got bad throbbing headache after it which lasted the rest of the day. This latter result brings us to what, from the practical standpoint, is the most interesting part of the research.

We believe it will be generally admitted that one of the commonest results of too free potations in the human subject is a bad throbbing headache, and it appears that the alcohol itself is only partly to blame for this dis. agreeable sequela. The aldehydes generally, and furfural particularly, play a very active part in the production of these headaches. This appears to be one reason why one is less liable to get a headache after old whiskey, for instance, than after new, or, speaking more correctly, No. I 638 , VOL. 63$]$ relatively new. One of the effects of maturation upon whiskey is to diminish the amount of furfural and aldehydes which it contains. This effect of maturation can apparently be effected by another means, viz., by distillation of the fresh spirit or of the low wines with phenylhydrazine-sulphonate. By this means the authors were able to obtain an aldehyde-free whiskey, and to watch the effect of it upon animals, comparing it with that of the same spirit before distillation. Their results are certainly interesting. They found that recovery from profound alcoholic, or rather whiskey, poisoning was distinctly different in the two cases. In the case of the original spirit, the animal, during the transition staye from drunkenness to sobriety, was restless, wandering from one part of the laboratory to another, and seemed, generally speaking, remarkably uncomfortable. Even when the gross symptoms of alcoholic poisoning had passed off the animal did not behave normally for some time ; it refused food offered to it, and showed marked signs of bad temper. These secondary symptoms werc entirely absent in the case of the aldehyde free spirit. When the animal was sober it appeared perfectly normal, and if offered food took it apparently with relish.

These symptoms, which cannot fail to remind one of the so-called "Katzen-jammer" of the German student, are, oddly enough, most markedly relieved by precisely those substances which contain chemical groups capable of combining with and rendering innocuous these same aldehydes. The most general substance used in this connection is either ammonia itself or some compound containing amido $\left(\mathrm{NH}_{2}\right)$ groups. The action of all morning "pick-me-ups," from the student's red-herring to the viveur's effervescing citrate of caffeine, is apparently explainable upon this hypothesis, viz., that they neutralise the alhedyde constituents of the potable spirits.

\section{THE ORIENTATION OF GREEK TEMPLES.}

A PAPER, "Some Additional Notes on the OrientaA tion of Greek Temples," an abstract of which was read before the Royal Society on February 14 , gave an account of six Grecian temples of which the orientation had been examined or re-examined during the spring of 1900. The chief observations and results described in the paper may be stated as follows :--

(I) The grotto sacred to Apollo on Mt. Cynthus, in the isle of I)elos, was interesting as being not improbably the very earliest existing structure of a religious character on Greek soil. The orientation seems, as usual, to have been connected with a zodiacal star, a Librie, and the date of the formation of the grotto derived from this is about 1530 B.C. The original foundation of temples in Greece on some other sites are, indeed, more ancient than this; but it is presumed, and in a good many cases can be clearly established, that in those cases what can be now seen and measured is that which remains of reconstructions following the same lines as the earlier works. But this grotto at Delos, the sides of which are formed by the natural rock, and the roof and doorway only are artificial, is probably the very shrine alluded to by Virgil as already ancient at the time of the Trojan war (Templaz dci saxo venerabar structa vetusto, Kin. iii. 84).

(2) At Delphi, where the clearance of the site by the French archeologists gave a better opportunity of examining the celebrated temple of Apollo, there is evidence of a change of orientation, one, evidently the more ancient, having the angle $231^{\circ} 18^{\prime}$, the other $227^{\prime \prime} 8^{\prime}$. These are the angles of the axis when looking east, measured from the south point round by west. The site is very peculiar, bein $_{5}$ surrounded by mountains. The sun must have illuminated the sanctuary through an opening on the flank, as was the case at Bassix, also dedicated to Apollo; 